\title{
QUÃO HETEROGÊNEO É O SETOR INFORMAL BRASILEIRO? UMA PROPOSTA DE CLASSIFICAÇÃO DE ATIVIDADES BASEADA NA ECINF*
}

\author{
Carmem Aparecida Feijo ${ }^{* *}$
}

\author{
Denise Britz do Nascimento e Silva ${ }^{* * *}$
}

\author{
Augusto Carvalho de Souza ${ }^{* * * *}$
}

\begin{abstract}
RESUMO O objetivo deste texto é apresentar uma classificação para a economia brasileira de setores de atividade segundo graus de precariedade na forma de organização da produção. O texto propõe critérios e uma classificação de atividades econômicas segundo três níveis de informalidade: alta, média e baixa. Nossa hipótese de trabalho é assumir que, assim como a fronteira entre o trabalho formal e o informal não é bem demarcada, dentro do setor informal também podemos identificar um continuum de situações em que os pressupostos de um trabalho decente estão mais ou menos presentes. Conclui-se que políticas públicas que visem a combater a informalidade devem buscar o crescimento econômico e atuar sobre as diferentes características das atividades informais.
\end{abstract}

Palavras-chave: informalidade; heterogeniedade estrutural; trabalho decente Código JEL: J8; L16

\footnotetext{
* Artigo recebido em 13 de junho de 2008 e aprovado em 15 de junho de 2009.

** Professora da UFF, doutora pelo University College London, e-mail: cfeijo@terra.com.br

*** Professora da ENCE/IBGE, licenciada, doutora pela Southampton University, e-mail: denisebritz@ gmail.com

**** Mestre pela ENCE/IBGE, doutorando no Cedeplar/UFMG, e-mail: augusto.ralph@gmail.com
} 


\section{HOW HETEROGENEOUS IS THE BRAZILIAN INFORMAL SECTOR? A PROPOSAL OF CLASSIFICATION OF ACTIVITIES BASED ON ECINF}

ABSTRACT The aim of this paper is to present a classification of sectors for the Brazilian economy according to different degrees of informality in the organization of the production. The paper classifies informal activities in three levels: high, medium and low informality. Considering that there is no clear line dividing formal and informal work, we assume that there is a continuum of situations where the characteristics of decent work are more or less observed. The paper concludes that to combat informality economic policy should pursuit economic growth and act taking in consideration the differences in the organization of the informal sector.

Key words: informality in labor market; structural heterogeneity; decent work 


\section{INTRODUÇÃO}

A preocupação com o crescimento da informalidade no mercado de trabalho no Brasil se intensificou nos anos 1990 a partir das transformações na estrutura produtiva decorrentes dos processos de abertura econômica e privatizações, principalmente. Em diversos estudos (Sabóia, 1999; Cacciamali, 2001; Feijo, 2003, dentre outros), autores apontaram para as transformações ocorridas nos processos de produção em consequência da maior exposição das empresas à concorrência externa. Assim, o tema da informalidade tem ganhado importância crescente nos debates sobre o mercado de trabalho no Brasil e sobre políticas sociais de combate à desigualdade e pobreza.

Em uma perspectiva de análise ampla, este texto se insere na preocupação sobre o entendimento de como o setor formal da economia se relaciona com o setor informal. Essa é uma discussão que remonta ao processo de desenvolvimento de economias latino-americanas que convivem, em sua grande maioria, com uma heterogeneidade no mercado de trabalho considerada estrutural.

Em termos específicos, o objetivo deste texto é apresentar uma classificação para a economia brasileira de setores de atividade segundo graus de precariedade na forma de organização da produção. Nesse sentido, a ótica de análise da informalidade estará centrada na empresa informal. ${ }^{1}$ Partindo dessa, ótica o texto propõe critérios e uma classificação de atividades econômicas segundo três níveis de informalidade: alta, média e baixa. Os critérios estabelecidos foram inspirados no paradigma do trabalho decente, da Organização Internacional do Trabalho (OIT). Nossa interpretação desse paradigma é de que ele reconhece que não há uma fronteira clara entre trabalho formal e informal, e sim um gradiente de situações variando da extrema precariedade em termos de condições de trabalho até condições em que o trabalho é protegido e bem organizado. Nossa hipótese de trabalho é assumir que, assim como a fronteira entre o trabalho formal e o informal não é bem demarcada, dentro do setor informal também podemos identificar um continuum de situações em que os pressupostos de um trabalho decente estão mais ou menos presentes. Assim, reconhecemos que o setor informal é bastante heterogêneo, e políticas públicas que visem a combater a informalidade devem buscar identificar as diferentes características das atividades 
informais. Para níveis mais baixos de informalidade, conclui-se que políticas de garantia de emprego são mais eficazes.

Dividimos este trabalho em três seções, além desta introdução e do resumo e considerações finais. Na seção 1 discutimos como evoluiu o conceito de informalidade e as recomendações sobre como mensurar a economia informal e o setor informal do ponto de vista da Organização Internacional do Trabalho (OIT). A seguir apresentamos, baseados em Cacciamalli (2007), como a literatura discute o desenvolvimento do setor informal em economias como a brasileira. Na seção 3 apresentamos os critérios empregados e a classificação de atividades segundo graus de informalidade nos setores da economia brasileira, a partir das informações da Pesquisa de Economia Informal Urbana (Ecinf) do IBGE. Com as informações do questinário da Ecinf que caracterizam o funcionamento dos negócios, construímos uma escala de informalidade. A classificação de atividades é construída a partir da aplicação da escala de informalidade aos microdados do levantamento estatístico da Ecinf de 1997. ${ }^{2}$

\section{INFORMALIDADE SEGUNDO A OIT}

O interesse pela proliferação de tipos de produção à margem da formalidade e por relações de trabalho informais em economias de mercado é tema que já vinha sendo discutido no âmbito internacional desde a década de 1970, com a Organização Internacional do Trabalho (OIT) desempenhando um importante papel. É relevante destacar, para o nosso propósito de classificar atividades produtivas segundo graus de informalidade, como evoluiu essa discussão. Em um primeiro momento, a OIT se refere ao ambiente de atividades produtivas e relações de trabalho informais como "setor informal". Identificavam-se no setor informal as atividades desempenhadas por trabalhadores pobres, mas que não eram admitidos como legais, registrados, protegidos ou regulamentados pelas autoridades públicas.

Ao longo do tempo, a percepção do problema da informalidade foi se alterando. Um momento importante que marcou o avanço na percepção do problema da informalidade pode ser identificado na $78^{\text {th }}$ Session of the International Labour Conference, em 1991, quando a OIT, como uma instituição multilateral e com grande influência nas escolhas de políticas públicas dos países-membros, deparou com o seguinte dilema: 
- ou a OIT deveria encarar o "setor informal" como um provedor e/ou mantenedor do emprego e da renda e, assim, incentivá-lo;

- ou deveria buscar oferecer regulamentação e proteção social àqueles que estão no "setor informal" e correr o risco de reduzir a capacidade desse setor em prover emprego e renda para uma força de trabalho em constante expansão.

Assim, ficou entendido que o papel da OIT deveria se orientar no sentido de combater as causas subjacentes à informalidade, e não só os sintomas, a partir de uma estratégia de política econômica e social, abrangente e multifacetada (OIT, 1991, p. 27/7-27/8). ${ }^{3}$ Isso implica dizer que a intervenção governamental com o objetivo de combater a informalidade não se resume à aplicação de políticas específicas sobre a atividade informal, mas envolve também a aplicação de medidas de política econômica com vistas à promoção do crescimento econômico como uma estratégia de saída da condição de subdesenvolvimento (Salm, 2005).

\subsection{Setor Informal $\times$ Economia Informal 4}

Apesar de ao longo do tempo a expressão "setor informal" ter sido bastante utilizada para se referir à parte da economia considerada informal, ela não é, segundo a OIT, a mais adequada, uma vez que não consegue abranger todo o caráter dinâmico, heterogêneo e complexo do fenômeno. O termo setor é mais comumente utilizado no sentido de descrever um grupo de indústrias específicas ou uma atividade econômica, o que não corresponde à realidade do fenômeno da informalidade no trabalho, que pode estar espalhada por toda a economia. Destarte, para que toda a diversidade da informalidade possa ser abrangida pela sua denominação, a OIT ressalta que a expressão "economia informal" no lugar de "setor informal" é mais apropriada, isso porque as diferenças entre aqueles trabalhadores que constituem a economia informal e os que têm seus direitos reconhecidos são bastante grandes, seja comparando-as pela ótica das unidades produtivas ou da posição na ocupação.

Todos os diversos grupos que constituem a economia informal devem apresentar pelos menos duas características comuns: devem ser não reconhecidos ou protegidos por leis ou regulamentações e tanto os empregados quanto os empregadores são caracterizados por um alto grau de vulnerabilidade. 
A OIT faz ainda duas observações importantes: (I) economia informal não pode ser confundida com atividade criminosa e (II) essa parte obscura da economia apresenta regras e regulações. No primeiro caso, é claro que há atividades criminosas na economia informal, mas isso não significa que toda atividade informal seja criminosa; na verdade, boa parte fornece produtos e serviços que são legais. Na segunda observação a OIT chama a atenção para o fato de que as pessoas envolvidas em atividades informais têm suas próprias regras e estruturas organizacionais do mercado, incluindo estruturas de ajuda mútua que, por exemplo, fornecem crédito, transferem tecnologia e experiência e organizam treinamentos; como a OIT diz, possuem sua "política econômica” própria.

\subsection{Trabalho decente}

A OIT na sua conceituação mais recente percebe a economia informal como função das características desejáveis em um trabalho decente, associando à ideia de informalidade a ideia de direitos trabalhistas. Reconhece-se que a definição de informal limitada a setor, baseada na estrutura da unidade produtiva, não abrange as diversas formas de ocupação: atípica, alternativa, precária, irregular etc., e nem mesmo garante que as pessoas engajadas em atividades em empresas consideradas informais tenham um padrão de vida baixo. Fazia-se necessário que outras formas de informalidade pudessem ser cobertas pela definição. A partir dessa discussão, a OIT constituiu a visão da economia informal que expandia o horizonte conceitual e possibilitou uma melhor compreensão do fenômeno da informalidade. Essa abordagem engloba uma perspectiva da informalidade a partir da ótica da ocupação, que considera, para a determinação da informalidade, o status no trabalho e outras características relacionadas à atividade desempenhada.

Dessa maneira, começa-se a determinar a economia informal em função das características de um trabalho decente, e a OIT especifica ainda que entre a economia formal e a informal não existe um limite claro que as separe. Da mesma forma, podemos sugerir que entre o setor formal e o informal da economia também não existe um limite claro e bem demarcado que os separe. $\mathrm{O}$ que se constata na realidade, principalmente em economias em desenvolvimento, é que existe um ambiente de oportunidades de trabalho contínuo que vai desde o emprego de mão de obra com limitadas chances de 
crescimento e de acesso à proteção social até um ambiente em que todas as características de um trabalho decente são encontradas. Nesse contexto, em que limites claros entre o formal e o informal não podem ser traçados, faz sentido definir um continuum em termos de melhoramento das relações trabalhistas e das condições de trabalho. Quanto mais próximo do limite inferior em termos de organização da produção e das condições de trabalho, mais adequado classificar o trabalho e a atividade produtiva como informais, e quanto mais próximo do limite superior, mais próximo de um trabalho decente. São quatro os componentes principais de um trabalho decente:

(1) Emprego;

(2) Seguridade social;

(3) Direitos trabalhistas;

(4) Diálogo social.

Os dois primeiros componentes de um trabalho decente se referem à quantidade e à qualidade da ocupação, enfatizando que condições decentes de trabalho devem existir para todos os tipos de ocuapção, independente de sua natureza - formal ou informal; que deve haver segurança no trabalho e condições de trabalho saudáveis e proteção contra diminuição na renda; em suma, "refer to opportunities, remuneration, security and conditions of work" (OIT, 2002, p. 2).

Os dois últimos estão relacionados com direitos fundamentais dos trabalhadores, de novo, independente de sua natureza. Esses quesitos se referem, principalmente, aos direitos relacionados à liberdade de associação, de não discriminação no trabalho, ausência de trabalhos forçados e de trabalho infantil em condições abusivas e o direito de participar e comprometer-se em discussões com empresários e autoridades governamentais.

Em suma, o conceito de trabalho decente oferece uma forma de mensurar o fenômeno da informalidade através da inserção da mão de obra na atividade produtiva. Essa forma de mensuração é o que define a economia informal.

\subsection{Setor informal e o paradigma do trabalho decente}

Considerando que melhores condições de ocupação e de proteção social são oferecidas em ambientes de trabalho mais organizados e formalizados, a economia informal se manifesta principalmente no setor informal. A defi- 
nição de setor informal mede a informalidade do trabalho sob a ótica da empresa, ou seja, a unidade de investigação estatística nesse conceito passa a ser o estabelecimento produtivo. Assim, como observa Hussmanns (2002, p. 3):

The conceptual framework for defining informal employment disaggregates total employment according to two different dimensions: type of production unit and type of job. Type of production unit is defined in terms of legal organization and other enterprise-related characteristic, while type of jobs is defined in terms of status in employment and other job-related characteristic.

Interpretamos que as formas de se identificar o setor informal - pela ótica da empresa - e a economia informal - que inclui a forma de inserção da mão de obra em empresas formais e informais — são bastante ricas para descrever estruturas produtivas em que se observa elevado grau de heterogeneidade na forma de organização da produção, como a brasileira. Enfatizamos ainda que o enfoque da informalidade como um ambiente contínuo de gradação em termos de oportunidade e qualidade da ocupação abre espaço para o entendimento do fenômeno da informalidade como relacionado e dependente da evolução do setor informal da economia. Ou seja, permite que se assumam a economia informal e o setor informal como partes integrantes da estrutura formal, coexistindo e se relacionando, subordinado ao processo de desenvolvimento da economia. ${ }^{5}$ Nesse sentido, a questão que se coloca a seguir é discutir como se desenvolve o setor informal.

\section{FONTES DE CRESCIMENTO DO SETOR INFORMAL}

A literatura sobre mercado informal de trabalho não é consensual sobre as razões da persistência do trabalhador informal e do setor informal em economias de mercado. ${ }^{6}$ Dada a importância da economia informal na geração de ocupações em economias em desenvolvimento, a informalidade no mercado de trabalho e na estrutura produtiva deve ser encarada como um fenômeno estrutural. Vale observar ainda que a informalidade tem sido constatada também em países industrializados (ou desenvolvidos) e de forma cada vez mais intensa.

A observância do setor informal em economias em desenvolvimento tem razões históricas. Sua presença e persistência estão ligadas ao elevado 
grau de heterogeneidade das estruturas produtivas dessas economias, ${ }^{7}$ que por sua vez encontra sua explicação na forma como se deu o processo de industrialização. Nessa perspectiva de análise, a evolução do capitalismo em economias retardatárias no processo de industrialização gera desequilíbrios entre o crescimento da oferta e demanda de empregos, bem como entre o perfil da mão de obra e os requisitos dos empregos oferecidos. Nesse contexto, o setor informal se reproduz pelo padrão de articulação entre as estruturas formais e informais.

Essa explicação, baseada no elevado grau de heterogeneidade das estruturas produtivas, enfatiza a complexidade das articulações de produção entre as unidades produtivas e seus desdobramentos em termos das relações de subordinação do setor informal ao padrão e ao processo de desenvolvimento capitalista e à expansão da produção capitalista em nível nacional e internacional (Cacciamali, 2007, p. 150).

A autora (p. 150-151) aponta que a subordinação do setor informal ao formal

é percebida pelo fato de o Setor Informal não poder avançar sobre o terreno explorado pela firmas capitalistas, que ao imprimirem sua dinâmica sobre o espaço econômico delimitam os interstícios passíveis de exploração pelas unidades de produção do Setor Informal, ou seja, definem-lhe os leques de suas possibilidades de oferecer produtos e serviços. O Setor Informal, no âmbito dessa dinâmica, mostra-se flexível e permeável, extinguindo e expandindo determinadas atividades, modificando, portanto, sua composição e suas relações com o Setor Formal, em virtude dos espaços ainda não ocupados, abandonados, criados ou recriados pela produção das firmas capitalistas, e suprindo demandas que não estão sendo atendidas pelas mesmas.

Dada essa descrição, a autora conclui que

o Setor Informal é composto por trabalhos e atividades que ocupam interstícios nos mercados de bens, que se moldam e se transformam ao toque das mudanças provocadas tanto pela expansão das firmas capitalistas que alteram a estrutura de oferta de bens, como pelo nível e composição da demanda por bens, construída pelo nível e distribuição da renda (op. cit., p. 151).

Além dessas causas estruturais, outro fator que tem contribuído mais recentemente para a expansão do setor informal é a mudança na estrutura produtiva, em razão da maior integração entre as economias, e nas relações trabalhistas. Tem-se observado nos anos 1990 um aumento da flexibilização 
e da informalização da produção e das relações de trabalho, isso em um contexto de competição global e de desenvolvimento de tecnologias de informação e comunicação (OIT, 2002). Essa particularidade marcante na década de 1990 tem feito com que cada vez mais firmas adotem formas de produção mais flexíveis, caracterizadas pela diminuição da utilização da mão de obra formal e aumento da participação de unidades produtivas mais flexíveis e especializadas, sendo algumas não registradas e informais.

No caso do Brasil, esse fenômeno tem aumentado de importância ao longo da última década. Com a abertura do mercado brasileiro à concorrência internacional no início da década de 1990, as empresas, principalmente as do setor de transformação, buscaram inovar as formas administrativas e diminuir custos visando a uma maior competitividade. Para o mercado de trabalho isso significou diminuição da demanda por trabalho.

Por conta disso e devido ao baixo dinamismo da economia brasileira nos anos 1990 e início da presente década, a força de trabalho se viu, muitas vezes, obrigada a "apelar" para o mercado informal. Isso fez com que a importância da economia informal tenha crescido, chegando a atingir em 2005, segundo estimativas das Contas Nacionais (Hallak et al., 2008, tabela 4, p. 12), mais da metade (58,8\%) dos trabalhadores brasileiros. ${ }^{8}$

$\mathrm{O}$ crescimento da informalidade ganha força à medida que a economia formal apresenta-se incapaz de gerar postos de trabalho suficientes para uma mão de obra em constante crescimento e também porque se torna, em muitos casos, impossível para um empreendedor constituir uma empresa que possa ser considerada formal. Nesse contexto, é cada vez maior o número de pessoas que veem na economia informal a única saída para a sobrevivência.

Assim, o ponto a destacar é que o setor informal se desenvolve de forma articulada e subordinada ao setor formal. Para evoluirmos esse argumento, nosso objetivo na próxima seção é, através da análise dos microdados de unidades produtivas da Pesquisa sobre a Economia Informal Urbana Ecinf, do IBGE, identificar características no modo de operação do setor informal. Nosso objetivo é propor uma gradação de informalidade segundo as condições de trabalho observadas nos diversos setores de atividade. Estaremos, assim, contribuindo para entender melhor a heterogeneidade do setor informal. 


\section{DEFINIÇÃO DE GRAUS DE INFORMALIDADE DAS ATIVIDADES ECONÔMICAS NO BRASIL}

Nosso objetivo nesta seção é identificar características no funcionamento das empresas informais que nos permitam classificar setores de atividade segundo diferentes graus de informalidade. Vale ressaltar que, como trabalhamos com o conceito de setor informal (que identifica a ocupação informal pela ótica da empresa), não estabelecemos uma correspondência direta entre os quesitos que usaremos para classificar uma empresa segundo diferentes graus de informalidade com os quatro componentes do paradigma do trabalho decente (conforme apresentado na seção 1.2).

A contribuição original do exercício que realizamos para classificar setores de atividade segundo grau de informalidade é extrair da Ecinf aquelas características no funcionamento dos negócios que nos permitam traçar a escala de informalidade. Assim como o conceito de trabalho decente não identifica uma linha divisória clara entre a ocupação formal e a informal, em termos de setores de atividade também podemos afirmar que não existe uma linha de fronteira clara. Isso nos permite identificar aqueles setores em que empreendimentos mais formalizados têm maior probabilidade de ocorrer e aqueles em que predomina a ocupação informal, do tipo estratégia de sobrevivência do trabalhador. Como podemos interpretar das seções anteriores, a articulação dos negócios informais com a economia formalmente organizada determina, em grande medida, o grau de vulnerabilidade dos negócios.

Através da Ecinf, identificamos como características do funcionamento do empreendimento um conjunto de seis componentes ${ }^{9}$ em relação aos ramos de atividade: ${ }^{10}$ (a) Nível de Receita; (b)Posição do Proprietário (conta própria ou empregador); (c) Local de Funcionamento; (d) Mercado Consumidor; (e) Controle de Contas; e (f) Constituição Jurídica. Podemos interpretar esses componentes como atributos básicos que permitem definir as condições da ocupação em cada tipo de negócio e, assim, o grau de informalidade da atividade. Os componentes nível de receita, local de funcionamento e mercado consumidor permitem caracterizar as condições de funcionamento da empresa, e portanto sua capacidade de geração e sustentação de empregos. O componente posição do proprietário, associado à informação 
sobre o controle das contas e constituição jurídica, indica o grau de acesso aos direitos trabalhistas. ${ }^{11}$

Em relação ao nível de receita dos negócios foram identificadas sete faixas, conforme detalhado no Anexo. As faixas menores correspondem à maior informalidade e as faixas maiores, à menor informalidade. A posição do proprietário é um critério usual para identificar o grau de fragilidade dos negócios informais, e atividades em que predominam trabalhadores por conta própria tendem a ser mais vulneráveis.

A localização do negócio também parece ser uma característica importante a identificar o grau de precariedade do empreendimento informal. A Ecinf identifica locais precários para o funcionamento de uma empresa, tais como o domicílio ou fora do domicílio, mas sem local fixo, como em via ou área pública.

Outra característica importante é distinguir as empresas que dependem de poucos clientes, o que gera maior insegurança, das que têm uma clientela diversificada. Também é relevante distinguir empreendimentos que vendem para pessoas e que vendem para instituições. Nesse caso, essa característica tanto pode funcionar como fonte de insegurança, por estar a empresa informal dependente de poucos clientes de grande importância para a sobrevivência do negócio, como fonte incentivadora de maior "profissionalismo" na gestão do negócio, devido às exigências feitas pela instituição, o que garante maior segurança e qualidade no desempenho das atividades. Essa característica exemplifica bem a interdependência do setor formal e informal, e a posição subordinada deste último ao primeiro.

O controle das contas do negócio ajuda a definir níveis de informalidade através da precariedade com que o negócio é gerenciado. Isso é feito diferenciando, nos extremos, as empresas que não registram, de forma alguma, as suas contas das que utilizam, de forma mais profissional, um contador.

A última área, status legal, contribui pouco para definir níveis de informalidade dentro do setor informal. Até porque a definição de informal utilizada na Ecinf deixa claro que esse quesito não é levado em consideração. ${ }^{12}$ Entretanto, o grau de legalização das empresas pode ser investigado dentro de cada nível de informalidade, e também é possível, de forma razoavelmente confiável, localizar os ramos cujas empresas se beneficiam da ilegalidade — concorrência desleal. 


\subsection{Graus de informalidade}

Assumindo que existe grande heterogeneidade no setor informal urbano brasileiro em relação às várias características de funcionamento do negócio, nosso próximo passo é classificar os setores de atividade econômica de acordo com a insegurança vivenciada pelo proprietário e seus dependentes e a precariedade nas condições de trabalho. Assim, foi possível criar grupos de ramos de atividade no setor informal (listados nos quadros 1, 2 e 3 ) de forma a expressar uma escala de informalidade, na qual se podem perceber os ramos que apresentavam uma proximidade maior ou menor com a formalidade. Categorizamos os ramos de atividade do setor informal urbano em 1997 no Brasil em três níveis, distribuídos da seguinte forma:

- alta informalidade, totalizando $48 \%$ do total de estabelecimentos, no qual os ramos de atividade se apresentavam em situação precária de funcionamento;

- média informalidade, totalizando $25 \%$ do total de estabelecimentos informais, no qual os ramos de atividade apresentavam situação intermediária; e

- baixa informalidade, com $27 \%$ do total de estabelecimentos, caso em que se encontravam os ramos nos quais as empresas estavam, claramente, em melhor situação, aproximando-se de características do setor formal da economia.

Esses graus de informalidade são descritos e os respectivos ramos de atividade são apresentados nos quadros a seguir.

\subsubsection{Alta informalidade}

Neste grupo (quadro 1), predominava o baixo nível de receita (níveis 1 e 2, principalmente; ver Anexo). As empresas costumavam ter suas atividades desenvolvidas nos domicílios, sobretudo sem local exclusivo, e quando atuavam fora do domicílio era sem local fixo, como em veículos e em áreas públicas.

Em relação ao perfil de clientes deste conjunto de atividades não é perceptível nenhum padrão específico, mas, em relação à contabilidade, está claro que a característica predominante era o não registro, que, quando feito, era realizado pelo próprio proprietário (sozinho). A ilegalidade também era característica comum. Todos os ramos eram muito associados à falta de constituição jurídica. 


\section{Quadro 1: Especificação dos ramos e setores de atividade de alta informalidade - número de empresas}

\begin{tabular}{|c|c|c|c|}
\hline & Setores e ramos de atividade & $\begin{array}{l}\text { Frequência } \\
\text { absoluta }\end{array}$ & $\begin{array}{l}\text { Frequência } \\
\text { relativa }\end{array}$ \\
\hline & Setor C - Indústria extrativa mineral & 15.736 & 0,17 \\
\hline & Setor D - Indústria de transformação & & \\
\hline D5 & Fabricação de produtos de madeira & 64.313 & 0,68 \\
\hline D8 & Fabricação de artigos de borracha & 856 & 0,01 \\
\hline D9 & Fabricação de produtos de material plástico & 3.054 & 0,03 \\
\hline \multirow[t]{2}{*}{ D10 } & $\begin{array}{l}\text { Fabricação de acessórios do vestuário e de segurança } \\
\text { profissional e preparação de couros e fabricação de artefatos }\end{array}$ & & \\
\hline & de couro, artigos de viagem e calçados & 32.593 & 0,35 \\
\hline D12 & Fabricação de produtos químicos inorgânicos e inorgânicos & 683 & 0,01 \\
\hline D13 & $\begin{array}{l}\text { Fabricação de resinas e elastômeros, fabricação de fibras, } \\
\text { fios, cabos e filamentos contínuos artificiais e sintéticos e } \\
\text { fabricação de produtos farmacêuticos }\end{array}$ & 614 & 0,01 \\
\hline D14 & $\begin{array}{l}\text { Fabricação de sabões, detergentes, produtos de limpeza } \\
\text { e artigos de perfumaria }\end{array}$ & $2.4670,03$ & \\
\hline D17 & Fabricação de bebidas e de produtos do fumo & 5.604 & 0,06 \\
\hline D19 & $\begin{array}{l}\text { Fabricação de equipamentos de instrumentação } \\
\text { médico-hospitalares, instrumentos de precisão e ópticos, } \\
\text { equipamentos para automação industrial, cronômetros e relógios }\end{array}$ & 99.861 & 1,06 \\
\hline $\mathrm{D} 20$ & No lar & 157.122 & 1,66 \\
\hline \multirow[t]{3}{*}{$\mathrm{D} 21$} & Confecção de artigos do vestuário e acessórios & 266.004 & 2,82 \\
\hline & Setor F-Construção & 1.544 .828 & 16,35 \\
\hline & Setor G - Comércio & & \\
\hline G5 & Ambulante e feira livre & 1.095 .186 & 11,59 \\
\hline \multirow[t]{2}{*}{ G6 } & Manutenção e reparação de artigos do vestuário e complementos & 386.645 & 4,09 \\
\hline & Setor I - Transporte, armazenamento e comunicações & & \\
\hline \multirow[t]{2}{*}{13} & $\begin{array}{l}\text { Transporte rodoviário de cargas, em geral, e atividades auxiliares } \\
\text { dos transportes terrestres }\end{array}$ & 80.804 & 0,86 \\
\hline & $\begin{array}{l}\text { Setor } \mathrm{K} \text { - Atividades imobiliárias, aluguéis e serviços prestados } \\
\text { às empresas }\end{array}$ & 487.662 & \\
\hline \multirow[t]{3}{*}{ K1 } & Vigilância e segurança por conta própria & & 0,23 \\
\hline & Setor M - Educação & 156.569 & 1,66 \\
\hline & Setor N - Saúde e serviços sociais & & \\
\hline \multirow[t]{2}{*}{ N1 } & Serviços sociais & 9.391 & 0,01 \\
\hline & Setor O - Outros serviços coletivos, sociais e pessoais & & \\
\hline \multirow[t]{2}{*}{$\overline{\mathrm{O} 1}$} & Atividades desportivas, cabeleireiros e outros tratamentos & & \\
\hline & de beleza e atividades de manutenção do físico corporal & 463.285 & 4,90 \\
\hline \multirow[t]{2}{*}{$\mathrm{O} 2$} & Limpeza urbana e esgoto e atividades relacionadas & & \\
\hline & e atividades funerárias e serviços relacionados & 2.207 & 0,02 \\
\hline \multirow[t]{2}{*}{09} & Atividades de organizações religiosas & & \\
\hline & e outras atividades associativas diversas & 7.167 & 0,08 \\
\hline 010 & Lavanderias e tinturarias & 57.713 & 0,61 \\
\hline \multirow[t]{2}{*}{011} & Exploração de jogos de azar, prostituição e atividades & & \\
\hline & de astrólogos, videntes e similares & 14.235 & 0,15 \\
\hline \multirow[t]{2}{*}{013} & Outras atividades de serviços pessoais & 49.433 & 0,52 \\
\hline & Total & 5.004 .032 & 48,03 \\
\hline
\end{tabular}

Fonte: Elaboração própria a partir da Ecinf. 


\subsubsection{Média informalidade}

Neste grupo de atividades (quadro 2), as receitas apresentavam-se medianas, variando em torno dos níveis 4 e 5 (ver Anexo). As empresas atuavam de forma equilibrada tanto no domicílio quanto fora dele e apresentavam

\begin{tabular}{|c|c|c|c|}
\hline & Setores e ramos de atividade & $\begin{array}{l}\text { Frequência } \\
\text { absoluta }\end{array}$ & $\begin{array}{l}\text { Frequência } \\
\text { relativa }\end{array}$ \\
\hline & Setor D - Indústria de transformação & & \\
\hline D1 & $\begin{array}{l}\text { Fabricação de produtos de minerais não metálicos } \\
\text { e de produtos de metal - exceto máquinas e equipamentos }\end{array}$ & 126.352 & 1,34 \\
\hline D3 & $\begin{array}{l}\text { Fabricação de material eletrônico e de aparelhos } \\
\text { e equipamentos de comunicações }\end{array}$ & 19.099 & 0,20 \\
\hline D4 & Fabricação de outros equipamentos de transporte & 5.689 & 0,06 \\
\hline D6 & Fabricação de móveis e indústrias diversas & 108.658 & 1,15 \\
\hline \multirow[t]{2}{*}{ D7 } & Fabricação de celulose, papel e produtos de papel e reciclagem & 3.329 & 0,04 \\
\hline & Setor G - Comércio & & \\
\hline G2 & Manutenção e reparação de veículos automotores & 344.629 & 3,65 \\
\hline G11 & Reparação de objetos pessoais e domésticos & 221.064 & 2,34 \\
\hline \multirow[t]{3}{*}{$\mathrm{G} 12$} & Representantes comerciais e agentes do comércio & 121.339 & 1,28 \\
\hline & Setor H - Alojamento e alimentação & 792.912 & 8,39 \\
\hline & Setor I - Transporte, armazenamento e comunicações & & \\
\hline 11 & Transporte rodoviário de passageiros, não regular & 245.666 & 2,60 \\
\hline 14 & Transporte aquaviário & 1.950 & 0,02 \\
\hline 17 & $\begin{array}{l}\text { Telecomunicações } A \text { - atividades de manutenção operacional } \\
\text { das redes de telecomunicações e serviço telefônico público } \\
\text { e os postos telefônicos }\end{array}$ & 8.006 & 0,09 \\
\hline \multirow[t]{2}{*}{19} & $\begin{array}{l}\text { Atividades auxiliares dos transportes e manutenção e reparação } \\
\text { de veículos automotores }\end{array}$ & 22.115 & 0,23 \\
\hline & $\begin{array}{l}\text { Setor } \mathrm{K} \text { - Atividades imobiliárias, aluguéis e serviços } \\
\text { prestados às empresas }\end{array}$ & & \\
\hline K2 & Atividades imobiliárias & 77.067 & 0,82 \\
\hline \multirow[t]{2}{*}{ K4 } & $\begin{array}{l}\text { Aluguel de veículos, máquinas e equipamentos sem condutores } \\
\text { ou operadores e de objetos pessoais e domésticos }\end{array}$ & 31.701 & 0,34 \\
\hline & Setor O - Outros serviços coletivos, sociais e pessoais & & \\
\hline 05 & Atividades recreativas, culturais e desportivas em geral & 105.832 & 1,12 \\
\hline $\mathrm{O6}$ & Atividades de teatro, música e outras atividades artísticas e literárias & 53.771 & 0,57 \\
\hline 07 & $\begin{array}{l}\text { Atividades de organizações empresariais, } \\
\text { patronais e profissionais e atividades de organizações sindicais }\end{array}$ & 446 & 0,01 \\
\hline 08 & Atividades de bibliotecas, arquivos, museus e outras atividades culturais & 76 & 0,00 \\
\hline \multirow[t]{3}{*}{012} & Atividades de rádio & 2.836 & 0,03 \\
\hline & Setor Q - Serviços Diversos & 107.520 & 1,14 \\
\hline & Total & 2.400 .057 & 25,41 \\
\hline
\end{tabular}

Fonte: Elaboração própria a partir da Ecinf. 
de forma geral o desenvolvimento das atividades produtivas em loja, escritório, oficina etc.

Quanto ao perfil de clientes, predominava uma clientela variada de pessoas e o controle das contas tendia a ser feito com maior cuidado, com uma presença maior de contadores, embora ainda prevalecesse o registro realizado pelo proprietário. Neste grupo a ilegalidade ainda era bastante expressiva, mas a constituição jurídica já era mais comum.

\subsubsection{Baixa informalidade}

Neste grupo (quadro 3), destacam-se setores de atividade com o maior nível de receita e a forte tendência de o negócio ter sido desenvolvido fora do domicílio e em local fixo. O perfil de clientes deste grupo é bem diferente dos demais, uma vez que os clientes institucionais desempenhavam um papel mais importante, chegando a ser o mais frequente em vários ramos.

Aqui, o não registro das contas do negócio era algo menos provável e a presença de contadores era bem forte. Quanto ao status legal, era forte a presença de empresas ilegais, mas a constituição jurídica já estava bem mais presente do que nos outros dois grupos. Pode-se dizer que o funcionamento da atividade produtiva neste conjunto de atividades se assemelha ao funcionamento de empresas formalmente constituídas.

Quadro 3: Especificação dos ramos e setores de atividade de baixa informalidade - número de empresas

\begin{tabular}{llrc}
\hline Setores e ramos de atividade & $\begin{array}{c}\text { Frequência } \\
\text { absoluta }\end{array}$ & $\begin{array}{c}\text { Frequência } \\
\text { relativa }\end{array}$ \\
\hline & Setor D - Indústria de transformação & & \\
\hline D2 & Fabricação de máquinas e equipamentos & 23.661 & 0,25 \\
\hline D11 & $\begin{array}{l}\text { Fabricação de tintas, vernizes, esmaltes, lacas e produtos } \\
\text { afins e fabricação de produtos e preparados químicos diversos }\end{array}$ & 2.623 & 0,03 \\
\hline D15 & Fabricação de produtos têxteis & 52.978 & 0,56 \\
\hline D16 & Fabricação de produtos alimentícios & 94.256 & 1,00 \\
\hline D18 & Edição, impressão e reprodução de gravações & 23.894 & 0,25 \\
\hline & Setor G - Comércio & & 1,25 \\
\hline G1 & Comércio relacionado a veículos & 545.056 & 5,77 \\
\hline G3 & Comércio varejista de produtos alimentícios, bebidas e fumo & 255.701 & 2,71 \\
\hline G4 & Comércio varejista de artigos do vestuário e complementos & 19.925 & 0,21 \\
\hline G7 & $\begin{array}{l}\text { Comércio atacadista de matérias-primas agrícolas, animais vivos; } \\
\text { produtos alimentícios para animais }\end{array}$ & 398.094 & 4,21 \\
\hline G8 & Comércio varejista de outros produtos & & \\
\hline
\end{tabular}




\begin{tabular}{|c|c|c|c|}
\hline & Setores e ramos de atividade & $\begin{array}{c}\text { Frequência } \\
\text { absoluta }\end{array}$ & $\begin{array}{l}\text { Frequência } \\
\text { relativa }\end{array}$ \\
\hline & Setor G - Comércio & & \\
\hline G9 & $\begin{array}{l}\text { Comércio varejista de material de construção, ferragens, } \\
\text { ferramentas manuais; vidros, espelhos e vitrais; tintas e madeiras }\end{array}$ & 55.438 & 0,59 \\
\hline \multirow[t]{2}{*}{ G10 } & Comércio varejista não especializado & 11.235 & 0,12 \\
\hline & Setor I - Transporte, armazenamento e comunicações & & \\
\hline 12 & Transporte rodoviário de cargas, em geral & 299.383 & 3,17 \\
\hline 15 & Transporte aéreo & 2.257 & 0,02 \\
\hline 16 & Correio e outras atividades de entrega & 103 & 0,00 \\
\hline \multirow[t]{3}{*}{18} & Atividades auxiliares dos transportes & 16.949 & 0,18 \\
\hline & $\begin{array}{l}\text { Setor J - Intermediação financeira, seguros, previdência } \\
\text { complementar e serviços relacionados }\end{array}$ & 25.970 & 0,28 \\
\hline & Setor K - Atividades imobiliárias, aluguéis e serviços prestad & mpresas & \\
\hline K3 & Atividades jurídicas e despachantes & 139.401 & 1,48 \\
\hline \multirow[t]{2}{*}{ K5 } & Serviços prestados principalmente às empresas & 218.231 & 2,31 \\
\hline & Setor $\mathrm{N}$ - Saúde e serviços sociais & & \\
\hline \multirow[t]{2}{*}{ N2 } & Atividades de atenção à saúde e serviços veterinários & 198.155 & 2,10 \\
\hline & Setor O - Outros serviços coletivos, sociais e pessoais & & \\
\hline O3 & Limpeza urbana e esgoto e atividades relacionadas & 75 & 0,00 \\
\hline \multirow[t]{2}{*}{$\mathrm{O} 4$} & Atividades desportivas e outras atividades relacionadas ao lazer & 7.463 & 0,08 \\
\hline & Total & 2.508 .714 & 26,56 \\
\hline
\end{tabular}

Fonte: Elaboração própria a partir da Ecinf.

\section{RESUMO E CONSIDERAÇÕES FINAIS}

O aumento da informalidade no funcionamento do mercado de trabalho nos anos 1990 no Brasil estimulou desde então o debate sobre as formas de reduzir a informalidade, quer seja através da revisão da legislação trabalhista, quer seja através de programas de apoio ao trabalhador e à microempresa, quer seja ainda através de políticas de estímulo ao crescimento econômico. Dados a relevância do problema da informalidade para a melhoria nas condições do funcionamento do mercado de trabalho no Brasil e o aumento da produtividade da economia, o IBGE, órgão oficial produtor de estatística do governo brasileiro, realizou pela primeira vez em 1997 pesquisa domiciliar sobre economia informal urbana. Os microdados dessa pesquisa, divulgados em 2003, foram a referência empírica para este trabalho. ${ }^{13}$

A grande diversidade da atividade informal, por um lado, e a heterogeneidade característica da forma de operação das atividades informais, por outro, e ainda a complexa articulação do setor formal e informal dificultam 
a implementação de políticas públicas horizontais com o objetivo de combater a informalidade. Nossa contribuição neste texto foi a de apresentar uma classificação de setores de atividades segundo graus de informalidade, partindo do pressuposto de que podemos identificar características de funcionamento de estabelecimentos informais e associá-las a uma referência central (caso prototípico). Variações no funcionamento dos estabelecimentos informais em relação às características relevantes permitem construir a classificação segundo os graus de informalidade.

A partir da definição de setor informal oferecida pela OIT, em que a unidade econômica é o ponto de referência da investigação empírica, ${ }^{14}$ procurou-se descrever aspectos específicos do setor informal urbano brasileiro e mostrar o quão diversa é a estrutura de funcionamento das empresas de propriedade de trabalhadores por conta própria ou empregadores com até cinco empregados. A conceituação da OIT de economia informal através da identificação das características de trabalho decente mostra que entre a economia formal e a informal não existe um limite claro que as separe. Define-se, assim, um continuum em que se observa um melhoramento das condições de trabalho à medida que se passa de uma estrutura produtiva menos organizada e frágil economicamente para uma estrutura mais organizada e sólida.

Apoiados nessa percepção, identificamos, a partir das características de funcionamento dos estabelecimentos informais (Nível de Receita; Posição do Proprietário; Local de Funcionamento; Mercado Consumidor; Controle de Contas; e Constituição Jurídica), um continuum de empresas com graus diferenciados de informalidade. Dos 68 setores e categorias de atividades da Ecinf, classificamos 25 como de alta informalidade (48\% do número total de empresas com até cinco empregados e trabalhadores por conta própria), 21 como de média informalidade ( $25 \%$ do total de unidades econômicas informais) e 22 setores como de baixa informalidade (totalizando $27 \%$ do total de observações).

A posição na ocupação dos trabalhadores informais é um dado bastante importante para definir o bom funcionamento da atividade produtiva. Em geral, as empresas de trabalhadores por conta própria apresentavam pior desempenho, local de funcionamento da empresa mais precário, gerenciamento mais deficiente e maior ilegalidade do que os empregadores. Isso significa que não se podem, ao analisar o setor informal, considerar de maneira equivalente essas duas características ocupacionais. $\mathrm{O}$ estudo revelou 
ainda que a capacidade de empregar é fator importante na determinação da qualidade da empresa informal e, portanto, na caracterização da heterogeneidade do setor informal urbano brasileiro.

$\mathrm{Na}$ construção da classificação de graus de informalidade proposta por este trabalho foi possível perceber que há também bastante heterogeneidade dentro das categorias ocupacionais. Nem todo trabalhador por conta própria apresentava uma situação de precariedade, e um continuum de qualidade da estrutura de funcionamento da empresa foi observado. Pôde-se notar, por exemplo, que os que atuavam nos ramos de Comércio varejista de material de construção, ferragens, ferramentas manuais; vidros, espelhos e vitrais; tintas e madeiras (G9), Comércio varejista não especializado (G10) e Atividades de atenção à saúde e serviços veterinários (N2) tinham seus negócios desenvolvidos de forma melhor do que, por exemplo, as empresas dos ramos de D20 (No lar), M (Educação) e G5 (Ambulante e feira livre).

O mesmo vale para os empregadores. Enquanto as empresas com até cinco empregados, por exemplo, dos ramos Fabricação de outros equipamentos de transporte (D4), Vigilância e segurança por conta própria (K1) e Comércio varejista não especializado (G10) apresentavam bom desempenho, as empresas dos ramos Construção (F), Fabricação de bebidas e de produtos do fumo (D17) e Fabricação de produtos de madeira (D5) tinham suas atividades sendo conduzidas de forma bastante precária.

Considerando-se a estrutura de funcionamento de empresas de trabalhadores por conta própria e empregadores de um mesmo ramo de atividade foram encontrados casos em que havia pouca diferença entre eles, como nos ramos da Construção (F), Fabricação de bebidas e de produtos do fumo (D17), Serviços sociais (N1) e Comércio varejista de material de construção, ferragens, ferramentas manuais; vidros, espelhos e vitrais; tintas e madeiras (G9), e situações em que trabalhadores por conta própria e empregadores exerciam suas atividades em condições bastante diferentes. Desta, são exemplos os ramos Fabricação de sabões, detergentes, produtos de limpeza e artigos de perfumaria (D14) e Fabricação de resinas e elastômeros, fabricação de fibras, fios, cabos e filamentos contínuos artificiais e sintéticos e fabricação de produtos farmacêuticos (D13).

Em resumo, este texto identificou em que setores de atividade a informalidade, segundo os critérios adotados, é mais acentuada. As atividades de alta informalidade devem estar associadas à estratégia de sobrevivência dos 
trabalhadores. Para esses casos, certamente políticas de capacitação de pessoal devem ser acompanhadas de políticas de garantia de emprego ou de renda mínima para apresentarem efeito positivo para reduzir a precariedade nas condições de trabalho. Em estabelecimentos de média informalidade, possivelmente políticas de fortalecimento da estrutura do negócio, através de políticas de crédito e qualificação profissional, podem surtir mais efeito na direção de melhoria nos ganhos e na produtividade. Finalmente, setores de baixa informalidade, cuja estrutura de funcionamento mais se assemelha a empresas formalmente constituídas, podem progredir à medida que uma legislação específica contribua para melhor funcionamento dos negócios e na articulação com o setor formal.

Uma recomendação importante decorrente da presente análise é a de que, dada a grande heterogeneidade do setor informal urbano brasileiro, resultado em grande medida do processo de industrialização, políticas públicas de combate à informalidade sejam diferenciadas considerando o grau de heterogeneidade da atividade produtiva e as características dos negócios informais e sua articulação com a estrutura formal da economia. Outra recomendação importante é que, dada a extensão da alta informalidade (presente em quase a metade dos setores de atividade), esta deve ser combatida através de políticas de garantia de emprego, a fim de efetivamente contribuir para a retirada de contingentes de trabalhadores da situação de elevada precariedade nas condições de trabalho. A persistência de um setor informal com peso expressivo na economia é entendida como resultado de uma estratégia de sobrevivência por parte de trabalhadores que não encontram colocação no mercado formal de trabalho. Nesse sentido, políticas de emprego devem estar associadas a políticas macroeconômicas que promovam o crescimento e devem ser consideradas como parte das políticas de inclusão social.

\section{NOTAS}

1. Essa ótica, a despeito de bastante abrangente, não incorpora a totalidade dos trabalhadores informais no país, pois não inclui aqueles em ocupações informais em empresas formais. A distinção conceitual entre medir informalidade pela ótica da empresa ou pela ótica da ocupação ficará clara na seção 1.1.

2. Segundo a Ecinf, pertencem ao setor informal todas as unidades econômicas não agrícolas de propriedade de trabalhadores por conta própria e de empregadores com até cinco empregados, moradores de áreas urbanas, sejam elas a atividade principal de seus 
proprietários ou atividades secundárias (IBGE, 1996). Dada essa definição, o setor informal descreve as formas de organização da produção que se mantêm em base ao trabalho não assalariado. O trabalho assalariado, caso exista, não é utilizado de forma regular ou permanente. A partir dessa conceituação, o setor informal passa a ser composto pelo conjunto de trabalhadores por conta própria, proprietários e sócios de unidades de produção que empregam trabalho familiar, mão de obra familiar, ajudantes e/ou trabalhadores que ocasionalmente trabalham para esses grupos.

3. OIT, 1991. Provisional Record. International Labour Conference, $78^{\text {th }}$ Session, Geneva, reply of the Director-General to the discussion of his Report.

4. Essa subseção tem como base principal ILO - International Labour Office, 2002. Decent work and the informal economy. International Labour Conference, $90^{\text {th }}$ Session, Geneva.

5. Ver a esse respeito Carneiro, 1989.

6. Uma referência para o debate sobre a informalidade, ver Ramos, 2007.

7. Sobre a heterogeneidade da estrutura produtiva na indústria brasileira nos anos recentes, ver Feijo e Carvalho, 2003.

8. O estudo dos autores, que avalia a informalidade através da ótica da empresa (setor informal), registra que 97,8\% das ocupações do setor de produção informal em 2005 caracterizavam-se como emprego informal. No setor de produção formal esse percentual foi de $22,6 \%$.

9. Os componentes foram identificados considerando a frequência das respostas no questionário da Ecinf.

10. No Anexo encontram-se descritos os blocos com as variáveis levantadas na Ecinf de 1997 sobre o funcionamento do negócio. Aplicou-se na realização do exercício desse texto um subconjunto das variáveis levantadas pela pesquisa, conforme assinalado no Anexo.

11. O método de estatística descritiva empregado para classificar setores de atividade segundo graus de informalidade foi a análise de correspondência. Através dessa técnica estatística é possível associar as várias características da empresa por meio de tabelas de contingência nas quais a interseção da linha $i$ com a coluna $j$ registra o número de empresas do setor informal que apresenta as características $i$ e $j$, conjuntamente. Duas características de interesse têm destaque para este trabalho: o setor de atividade da empresa e seu desempenho em termos da receitas. Essas duas características foram utilizadas como referência nas análises das demais tabelas de contigência para classificar as atividades por grau de informalidade. Os gráficos de correspondência que deram origem à classificação proposta encontram-se em Souza, Feijo e Silva (2006).

12. "Embora útil para propósitos analíticos, a ausência de registros não serve de critério para a definição do informal na medida em que o substrato da informalidade se refere ao modo de organização e funcionamento da unidade econômica e não a seus status legal ou às relações que mantém com as autoridades públicas" (IBGE, 1996).

13. A Ecinf foi realizada novamente em 2003.

14. Que é adotada pela Ecinf do IBGE. 


\section{ANEXO}

O questionário da Pesquisa sobre a Economia Informal Urbana - Ecinf de 1997, identifica 12 blocos de perguntas que tratam de características de funcionamento de estabelecimentos do setor informal. Assinalamos com asterisco as que foram utilizadas para caracterizar os graus de informalidade no presente texto.

1. Local de funcionamento*

\begin{tabular}{l}
\hline 2. Investimento \\
\hline 3. Clientela* \\
\hline 4. Terceirização \\
\hline 5. Lucratividade* \\
\hline 6. Acesso ao crédito/financiamento (últimos 3 meses) \\
\hline 7. Desempenho do negócio (últimos 12 meses) \\
\hline 8. Dificuldades enfrentadas \\
\hline 9. Planos para o futuro \\
\hline 10. Recebimento de assistência \\
\hline 11. Controle das contas* \\
\hline 12. Constituição jurídica*
\end{tabular}

A seguir, a lista de possibilidades de respostas em cada bloco.

*1. Local de funcionamento da atividade (variáveis V4302, V4303 e V4304)

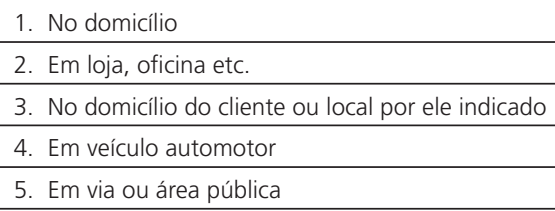

2. Investimento: Forma de obtenção da maioria dos equipamentos e/ou instalações próprios (variável V4317)

\begin{tabular}{l}
\hline 1. Comprou de empresa \\
\hline 2. Comprou de particular \\
\hline 3. Importou \\
\hline 4. Construiu/adaptou \\
\hline 5. Doação
\end{tabular}




\section{*3. Clientela}

\begin{tabular}{ll}
\hline Como se compõe (variável V4321) & Principais clientes (variável V4322) \\
\hline Um cliente (empresa) & Pessoas \\
\hline Clientela fixa & Empresas grandes \\
\hline Clientela variada & Empresas pequenas \\
\hline & Órgãos do governo e outras instituições \\
\hline
\end{tabular}

4. Terceirização: outras empresas ou pessoas processam

o produto e o devolvem à empresa (variável v4330)

$$
\text { 1. Sim }
$$

*5. Lucratividade: receita (em R\$) (variável V4903)

\begin{tabular}{l} 
Faixas de receita: \\
\hline 1. Até 120 (0 a 1 Salário mínimo) \\
\hline 2. 120 a 240 (1 a 2 Salários mínimos) \\
\hline 3. 240 a 360 ( 2 a 3 Salários mínimos) \\
\hline 4. 360 a 720 (3 a 6 Salários mínimos) \\
\hline 5. 720 a 1.320 (6 a 11 Salários mínimos) \\
\hline 6. 1.320 a 2.520 (11 a 21 Salários mínimos) \\
\hline 7. 2.520 ou mais (21 ou Salários mínimos mais)
\end{tabular}

\section{Acesso ao crédito: Se utilizou ou não e principal fonte de crédito/ financiamento/empréstimo (últimos 3 meses) (variáveis V4337 e V4339)}

1. Não utilizou empréstimo, crédito ou financiamento

2. Utilizou empréstimo, crédito ou financiamento

\section{Desempenho do negócio (últimos 12 meses) (variável V4359)}

1. Aumento/redução no número de pessoas ocupadas

2. Aumento/redução da capacidade produtiva (equipamento e instalação)

3. Diversificação/redução das atividades

4. Ampliação/redução/manutenção da jornada de trabalho 


\section{Dificuldades enfrentadas (últimos 12 meses) (variáveis V4360 e V4361)}

\begin{tabular}{l} 
1. Não teve dificuldade \\
\hline 2. Concorrência muito grande \\
\hline 3. Falta de recursos financeiros \\
\hline 4. Baixo lucro \\
\hline 5. Problemas de infraestrutura \\
\hline 6. Problemas com a fiscalização e/ou regularização do negócio \\
\hline 7. Problemas com a mão de obra (qualificação e rotatividade) \\
\hline 8. Escassez ou má qualidade das matérias-primas \\
\hline 9. Necessidade de treinamento gerencial \\
\hline 10. Outras
\end{tabular}

\section{Planos para o futuro no negócio (variável V4362)}

1. Continuar ou aumentar negócio no mesmo nível

2. Mudar de atividade e continuar independente

3. Abandonar a atividade e procurar emprego

4. Outro (especificado)

10. Recebimento de assistência (últimos 5 anos) (variáveis V4363 e V4364)

1. Não recebeu

2. Recebeu alguma assistência

*11. Controle das contas (variável V4342)

\begin{tabular}{l} 
2. Não registra nada \\
\hline 4. Registra sozinho \\
\hline 6. Tem contador \\
\hline 8. Outra forma (especificado)
\end{tabular}

* 12. Constituição jurídica (variável V4342)

0. Não tem

1. Tem 


\section{REFERÊNCIAS BIBLIOGRÁFICAS}

CACCIAMAli, M. C. Padrão de acumulação e processo de informalidade: Brasil e México. Pesquisa \& Debate, PUCSP, São Paulo, v. 12, n. 1, p. 5-43, 2001.

. (Pré-) Conceitos sobre o setor informal, reflexões parciais, embora instigantes. Comentários ao artigo. Econômica (Niterói), v. 9, p. 145-168, 2007.

CARNEIRO, F. G. O setor informal urbano no Brasil e o conceito de integração do mercado de trabalho. In: ENCONTRO NACIONAL DOS CENTROS DE PÓS-GRADUAÇÃO EM ECONOMIA, 17. Anais. ANPEC: Brasília, v. 3, 1989.

FEIJO, C. Produtividade do trabalho e emprego: o duplo desafio para os próximos anos. In: SICSÚ J.; OREIRO, J. L.; DE PAULA, L. F. (Org.). Agenda Brasil: políticas econômicas para o crescimento com estabilidade de preços. Barueri : Manole, 2003.

FEIJO, C. A.; CARVALHO, P. G. M. 2003. Heterogeneidade intra-setorial da produtividade do trabalho na indústria brasileira nos anos 90. Revista de Economia Contemporânea, Rio de Janeiro, v. 7, n. 2, p. 213-236.

IBGE. Economia Informal Urbana 1997 - microdados. Rio de Janeiro, IBGE, 2003a. 1 CDROM

. Economia Informal Urbana. Metodologia. Rio de Janeiro, IBGE, 1996.

HALLAK, J. et al. Setor e emprego informal no Brasil: análise dos resultados da nova série do sistema de contas nacionais. Texto para Discussão, Rio de Janeiro: IBGE, n. 31, Conac, 2008.

HUSSMANNS, R. A labour force survey module on informal employment (including employment in the informal sector) as a tool for enhancing the international comparability of data. Sixth Meeting of the Expert Group on Informal Statistic (Delhi Group). Rio de Janeiro, 16-8 set. 2002.

IBGE. Economia Informal Urbana 1997 - microdados. Rio de Janeiro, IBGE, 2003a. 1 CDROM.

ORGANIZAÇÃO INTERNACIONAL DO TRABALHO (OIT). 2002. Decent work and the informal economy. International Labour Conference, 90th Session, Geneva, Disponível em: www. ilo.org. Acesso em: 02 de maio de 2003

Decent Work. 1999. Report of the Director-General. International Labour Conference. 87TH Session: Geneva, June/1999. Disponível em: <www.ilo.org.> Acesso em: 2 de maio de 2003.

Provisional Record. 1991.International Labour Conference, 78th Session, Geneva, reply of the Director-General to the discussion of his Report. Disponível em: <www.ilo. org >. Acesso em: 2 de maio de 2003.

RAMOS, C. A. 2007. Setor informal: do excedente estrutural à escolha individual. Marcos interpretativos e alternativas de política, Econômica, v. 9, n. 1, p. 115-138, jun.

SABÓIA, J. Modernização e redução do tamanho dos estabelecimentos da indústria da transformação no passado recente. Econômica. Niterói, v. 1, n. 1, p. 53-74, jun. 1999. 
SALM, C. Estagnação econômica, desemprego e exclusão social. In: SICSU, J. DE P. L. F.; MICHEL R. (coordenadores), Novo-Desenvolvimentismo, Manole e Fundação Konrad Adenauer. 2005.

SOUZA, A. C.; FEIJO, C.; SILVA, D. B. DO N. Níveis de Informalidade na economia brasileira. Revista Econômica do Nordeste, v. 37, n. 3, jul.-set., p. 422-444. 2006. 